\title{
ALCOHOLIC PARESIS AND INFECTIOUS MULTIPLE NEURITIS.
}

\author{
By Dr. TH. TILING, \\ Director of the Rothenberg Asylum. \\ Translated BY DR. W. A. McCORN, \\ Formerly Assistant Physician, Illinois Eastern Hospital; Assistant Phy- \\ sician, McLean Hospital, Waverley, Mass.
}

The description, which to-day is given of infectious multiple neuritis, evidently corresponds almost exactly with that of alcoholic paresis of the older authors. The French, especially, describe alcoholic paresis clearly and sharply, as may be seen from Charcot's lectures. But the characteristic somatic and psychical traits have escaped neither English nor German writers. The psychical disorder is usually outlined briefly, but it is very simple and nearly embraced in the term disordered memory, so that a mistake or a misconception is hardly possible. Since Leyden's work, ${ }^{2}$ multiple neuritis has been studied with zeal and success; but it seems as if it had escaped the authors that the majority of cases of neuritis described were alcoholic paretics with the characteristic mental disorder. It is Korsakow's merit to have proven this fact. ${ }^{2} \mathrm{He}$ emphasized the necessary homogeneousness of neuritis and the mental disorder and further raised the claim that it was always due to infection as well as to alcoholic intoxication; as also to auto-infection, when waste products were retained in the body, and finally to intoxication by metallic poisons. According to him the mental disorder may occur in three forms: I, as irritable weakness of the whole nervous system with attacks of anxiety, 2, as general confusion, or finally, 3, as amnesia with pseudo-reminiscences. In my first work on the mental disorder observed in alcoholic multiple neuritis (Allg. Zeitschr. f.

${ }^{1}$ Neuritis und Poliomyelitis, Zeitschr. f. klin. Med., Bd. I, I880.

${ }^{2}$ Westnik, die klin. und gerichtl. Psych. und Neurol., 1887. 
Psych., Bd. 46, Heft 2 und 3, I889), I said that neuritis and amnesia together constitute the type of the disease, that this disease rarely arises from other causes than alcoholic excess, and that I can only regard the pure amnesia as characteristic of the neuritic mental disorder. Brie ${ }^{3}$ reported a case of neuritis after weeks of diarrhœa with vomiting, Hoevel ${ }^{4}$ a case of post-typhoid acute amnesic dementia with polyneuritis, Giese and Pagenstecher ${ }^{\text {" de- }}$ scribe a case arising from excess in drinking, with tuberculosis; Möbius ' describes two cases of puerperal neuritis which occurred similarly to the alcoholic and cites a case from Feriol, occurring during pregnancy, with uncontrollable vomiting and recovery after delivery. Redlich ${ }^{7}$ in one of his two cases ascribes the polyneuritis to intestinal trouble; but both cases have alcoholic neuritis. The latest Russian author, Suchanow; presents seven typical cases, of which two were of non-alcoholic origin, one occurring after a liver trouble and the other after post-typhoid parotitis.

These few quotations may suffice to show that the authors correctly follow Korsakow's opinion, that besides alcohol various auto-intoxications can produce the type of multiple neuritis with amnesic mental disorder. I have already described two such cases, one in the work cited, after gangrene of the foot and the other after post-typhoid perityphlitis." The question whether metallic poisons can produce such a symptom complex seems still unsettled. Cases with transient mental disorder in polyneuritis, e. g. after chronic lead poisoning ${ }^{10}$ do not correspond to the type described.

Further observations will show whether the neuritis with amnesic mental disorder produced by puerperal, typhoid, gangrenous and other processes corresponds exactly with the chronic and

${ }^{3}$ Brie, Mittheilungen auf d. 45 ord. Vers., etc., Allg. Zeitschr. f. Psych., Bd. 48, Heft I und 2, 1891 .

- Hoevel, Jahrb. f. Psych., Bd. IX, Heft 3, 1892.

- Arch. f. Psych., Bd. XXV, Heft 3, 1893.

- Neurolog. Beiträge, Heft IV, 1895.

'Wien. klin. Wochenschrift, No. 25, 1896.

- Arch. f. Psych. und Neurol., Bd. XXV, No. 3 und Bd. XXVI, No. 203.

Allg. Zeitsch. f. Psych., Bd. XLVIII, Heft 6, 1892.

${ }^{20}$ Possett, Wien. med. Wochenschrift, No. 22, 1895 . 
generally incurable alcoholic neuritis or alcoholic paresis. The status praesens, it must be admitted, is the same. To acquire a correct picture of the development and significance of alcoholic paresis it is not sufficient to examine and describe a fully developed alcoholic neuritis, but we must go back a step and consider the first mild effects which alcohol generally produces on the central nervous system, particularly upon the mental functions. I must here refer to facts compiled in W. Babilée's "dissertations. The work contains a large number of observations in part his own, in part those of the best known French alienists, like Voisin, Ball, Falret, Legrand du Saulle, etc. This abundant material shows that in people who are addicted to the regular use of alcohol, defects of memory in all grades, from mild dysmnesia to complete amnesia, are very commonly observed. This dysmnesia is often limited to a failure to remember dates, names, numbers, addresses, quotations; still the amnesia may attain the highest grade, and besides certain changes of character, moroseness, capriciousness, violence, depression or hypochondria may be observed. Digestive disorders, insomnia, etc., are added as physical troubles. These persons often fail in their occupation and must be reminded of their daily obligations by artificial aids to memory. Habitual duties may be performed according to their ald routine. A complete cure of the disorder at this stage seems to be one of the greatest rarities. Freudn's work," "Recognition of general enfeeblement of memory," from the German may be included. In Russian literature in the works from Korsakow and Suchanow cited are found several cases of neuritic manifestations but feebly indicated with the intimation that such cases are to be included in the same category as the fully developed cases. I call to mind a musical director, who after years of alcoholic excess, was unable to perform his duties until his wife took him to his place at the proper time and put the music before him. When he arose it was possible for him to conduct the orchestra in the usual manner to general satisfaction. The man complained of general weakness and pains in his calves, which made walking difficult. At that time no works on multiple

\footnotetext{
${ }^{11}$ Des troubles de la mémoire dans l'alcoolisme et plus particulièrement de l'amnésie alcoolique, Paris, 1886.

12 Arch. f. Psych., Bd. XX.
} 
neuritis had appeared. If such rudimentary symptoms were observed more in general practice it would then be shown by large numbers of examples that alcohol has an especially deleterious effect on the memory, and that it similarly affects the character. But it may be claimed to-day that alcoholic neuritis occurs only when a condition has been prepared for it. On careful examination of an alcoholic neuritic it will be found, without exception, that, whether with or without attacks of delirium, he has long tended toward amnesic dementia, even when the paralysis has occurred somewhat suddenly. How it may be with other forms of intoxication neuritis, the future must show after more careful investigation. The onset of a posttyphoid or puerperal neuritis is apparently sudden and unexpected. This type of amnesic mental disorder occurs without premonition. The acute onset of this disease is to be regarded as more severe as it is not a matter of inflammation or due to an acute inflammation of the peripheral nerve trunks according to the previous anatomical investigations in multiple neuritis, but to degeneration or destruction of the nerve fibres and the perineurium, as will be shown later. The premonitory stage of this neuritis seems to be non-febrile, like that of alcoholic neuritis. From this point of view chronic intoxications by metallic poisons, like arsenic, lead, bisulphide of carbon, etc., seems more readily comprehensible. Answers to these questions must be reserved for the future.

The number of reported cases of alcoholic neuritis and of polyneuritis has grown so at present that a type of disease can be spoken of, and hence I present a typical case of this sort not yet reported, and will pass on to a description of the disease.

On October I5th, I89I, a patient was admitted to the asylum at Rothenberg. He was 49 years old, a jurist and the city attorney of $M$. The patient, who was quite stout, clumsily entered the room on crutches and sank into a chair. Nothing abnormal was to be noticed in his face, eyes and speech; he talked fluently and rapidly; he had decided to come here to please his wife, but on the whole he did not feel very sick. When asked to stand up he succeeded only by supporting himself with the chairback; on being requested to assume a squatting position he fell completely. The extensors of the upper and lower thigh, and to a less extent the extensors of the upper extremities, were powerless, wasted and painful on pressure. On walking across the room his knees occasionally 
gave way. On raising his foot the toes dragged and were suspended by the action of the extensors with a slight tremor. The balls of the feet touched the floor first, then the heels. Sensation in the extremities was blunted and sensitiveness to pain was delayed; but later, sensation was acute and occasionally recurred spontaneously. The patellar reflexes were absent. When questioned as to his muscular strength, particularly of his legs, he asserted that he was a noted pedestrian: "Yes, Doctor, I am an old hunter, have tramped over the moor and marsh all day; my legs are strong."

After the patient had shown his displeasure because his wife had left him without bidding him good-bye, his humor very soon changed while in conversation with those about him. Within a quarter of an hour he very courteously offered his empty cigar case to those present five times, always apologizing when it was found to be empty. He repeated his hunting stories several times. At supper time he asked for whiskey and a small bottle of beer; as it was refused he affirmed that he had not been a drinker, "but every Courlander drinks whiskey;" "a bottle of beer could only benefit his anemia." This request, in consequence of its constant repetition, was met by the attendants by telling him that he had had both. Then he was satisfied. After supper he engaged in a game of cards; during which he often asked for cognac and beer and repeatedly called the waiters, as he fancied he was in a saloon.

According to the above report it must be clear that he had a so-called neuritis with amnesic mental enfeeblement, and without a history the assumption of alcoholic paresis would not be amiss.

The anamnesis showed that the patient was of healthy parents and had always been well. He was naturally frivolous, had become addicted to drink when a student and had continued it since. Of late years he had drank beer and cognac in the forenoon; for about two months his colleagues noticed his absent-mindedness, forgetfulness and great irritability. His wife noticed two weeks ago that it took him a long time to read a professional document. In the evening she asked him if he had finished it, and he affirmed that he had. The next morning he knew nothing of it. He drank repeatedly, partly because he did not know that he had already drank.

The further course of the trouble will be reported as briefly as possible.

He slept poorly in spite of two grams of chloral hydrate. The day after his admission he required to be kept in bed. His knees had given out several times in walking across the room, and on October 16th he first wrenched his right then his left ankle, in spite of being forbidden to arise. Both ankles were very painful. His desire for drink remained unchanged; on repeated refusal of spirits he remarked: "But, Doctor, yesterday and to-day I have drank beer in your presence, why should I not get it now? It can only benefit my anemia." He forgot his wife's visit in an hour; he called the nurses waiters; to his special nurse he gave the name of his former servant, and desired that he should always be at his bedside on the physician's visit to give information as 
to sleep, bowel movements, etc. The weakness of the extensors especially and the pain from pressure increased, his pulse varied between 96 and 104, his appetite failed, and he looked miserable and haggard. On November 5th dyspncea with subjective feelings of coldness occurred; his whole body trembled, his feet and hands were like ice. The pulse was accelerated; the temperature normal. A similar attack occurred on November 12th; he claimed to feel shooting pains in his left arm. He sighed, groaned and finally exclaimed, "Take the iron clamps off my hands. I suffocate; someone is choking mel" Respiration was difficult, his pulse markedly intermittent, his face suffused, and his eyes staring. In his distress the patient mistook his surroundings. These attacks lasted from one-half to one hour, and recurred on November 24th, December 2nd, 7 th, 9th, and 25th in nearly the same way. In the last attack the patient started up in bed at an accidental noise and exclaimed: "What is thatl Ah, there stands the grave-digger (pointing to a nurse); send him away, I am still alive! Why does the coffin-lid stand there? Take it away; oh, a yellow coffin! How cold! my feet are like ice!" Thus it continued; the crisis of the disease was passed about this time. From this time the patient had marked perversions of sensation. He pulled or picked at the bedding, or picked various objects from his fingers, worms with legs and scales, rings which he asked to be put away to be kept, etc. He believed he had warts on his fingers or felt a creeping sensation. On his worst days he was often comatose. On November 8th he told his wife he had been disturbed in the night by the cries of a Russian who maltreated his daughter (a patient under him had been noisy in the night). In spite of being told this he claimed it was the Russian, for he had been told so and that he had recognized his voice. The last of February, 1895, his condition improved. The sensations ceased and the muscular strength of the extremities increased, so that he could walk again, although with great difficulty and in the characteristic way. His memory improved somewhat. Early in March he was informed that owing to lack of means he would be transferred to a custodial institution at Mitau. He became excited, for he knew the institution, and as city attorney formerly had to inspect it. From this time on he became greatly depressed; at first he interpreted this decision of his family to mean that he probably had softening of the brain, was incurable and they wished to get rid of him entirely. Within an hour he reiterated this idea five times, in spite of the assurance that he would not become incurably deranged. Those about were obliged to console him continually; he shed tears. The same thing occurred on the following days; but to the repeated assurances he replied: "How is it? You have expressly told me that I have softening of the brain; how else should I get the idea, or am I crazy and fancy such things?" So it continued; he constantly interpreted the conversation of those about that incurable mental disorder induced his family to send him to Mitau. On March 8th he was taken from the institution.

On April 29th, 1896, the patient visited the institution alone. His 
appearance is lamentable; he is poorly nourished and changed; his hands especially emaciated, the interosseous spaces being sunken; his grip feeble; his gait unsteady, tottering, and his reflexes absent. Nothing abnormal is noticed in the muscles of the face; his speech is fluent and glib. With tears he told that his wife had petitioned the court for his disfranchisement in order to secure a separation afterwards, that his daughter no longer recognized him when she met him (this story agreed with the facts as far as could be learned). He further stated he had come to see if he could not be admitted to the third class in the institution. He asked if he came voluntarily could he not be discharged at any time on his request. As he was wholly without means, he begged to be admitted to the cheapest class, at 40 rubles a month. He would gladly share a room with another patient; could it not be G., whom he remembered when he was here before? On being told that there was no class of patients at 40 rubles, besides that his desire could not be granted, he still returned to the same point more than once. He then asked for paper to reckon how much it would cost, how much food he would receive, etc. He asked several times if it was advisable for him to be admitted, although assured that in his present condition he could live outside of an institution. $\mathrm{He}$ is of the opinion, and so remains, that he has softening of the brain, although it has been repeatedly contradicted. Thus ended this visit.

This case, as described, presents in great purity all the symptoms that have been described by French, German and English writers as alcoholic paresis, and is now described as alcoholic neuritis, i. e. as infectious polyneuritis. It has already been shown that neuritis of this type fits the dominating role that has been assigned to it; in my opinion it has no greater significance than the intestinal ulcers in typhoid, although like these, it is usually apparent, and the most accessible on examination. But according to the latest researches, neuritis must share this role with a myositis, which apparently is not secondary, but simultaneous and equivalent. I now pass to the description of the disease.

Almost always without premonitory symptoms of alcoholism, like delirium tremens, the individual experiences a blunting of his mental faculties, particularly of memory. The memory disorder is of so high a degree that a continuation of his occupation is out of the question. Perhaps greater irritability and violence, and also episodes of depression with anxiety are noticeable. Quite suddenly sensory and motor symptoms like pains in the legs, particularly the calves, also in the shoulders and upper ex- 
tremities, where several points are sensitive to pressure in the area of the cruralis, peroneus, radialis and ulnaris are associated with them. Perverse sensations accompany these pains. Soon the muscles are also sensitive to pressure, and the patient complains of general weakness and oppression. The muscle force is objectively lowered, while the paresis of the extensors, chiefly of the lower, then of the upper extremities is especially striking; several fingers occasionally hang flaccidly and cannot be extended. The paralysis also affects the abdominal muscles and renders bearing down impossible. Examination in this stage shows that the sensibility is blunted and the most markedly in the periphery, passing upward without sharp boundaries; it is increased here and there and occasionally amounts to anaesthesia without being confined to definite nerve tracts. The prick of a needle in these places causes no feeling of pain; but it often occurs after a few seconds and gradually becomes intense, disappears to occasionally return spontaneously (retardation and recurrence). The patient always seems to be very sensitive to cold. The senses of location and temperature are absent. But this condition is not constant in the same individual, but changing at different times. In the motor sphere a flaccid, atrophic and likewise painful paresis exists and occasionally paralysis of several small muscles of the hands and feet. The dorsal flexion of the hands and feet is weak, occasionally absent, the volar flexion is better, spreading and adduction of the fingers can only be performed to a slight degree, or only adduction is possible; it is the same with the opposition of the thumb, etc. Electrical examination (faradic as well as galvanic irritation and likewise if directly or indirectly applied) shows for strong currents medium, weak, even no reaction or that of degeneration. The tibialis posticus, peroneus, radialis nerves and the recti femoris, vasti interni and externi, tibialis, extensor digiti communis, peronei, gastrocnemei, interossei, balls of the thumb and little finger, extensor carpi radialis longus, extensor indicis, digiti minimi and several other muscles are especially affected. The reaction varies in proportionately short periods. The tendon reflexes are weak or absent; by tapping the muscles numerous twitchings occur, often in the extensors. The muscles have a doughy feeling. On the whole the paralysis is ascending and in severe cases will affect the trunk 
and respiratory muscles, when paroxysms of dyspnœa will occur and death in some cases. The cranial nerves and muscles of the face, tongue and throat are very rarely or only exceptionally affected. This is a picture of the sensory and motor symptoms at the climax, which generally lasts for months with fluctuations. A gradual improvement then occurs. Still the pulse is constantly accelerated to $100-120$.

When the study of the sensory and motor disorders indicates besides the strictly localized, much diffuse damage, like the blunted and retarded sensitiveness to pain, extended over almost the whole body, and general paresis, it necessarily leads to the assumption of a central disorder of the psychical sphere. On close inspection this is probably manifested before the others. The form of the mental disorder is extremely simple, easily recognized and differentiated from others. In general it may be described as a primary mental enfeeblement, but it differs essentially from every other form of mental enfeeblement. A fundamental function of the mind here suffers in particular, the memory and the others secondarily sympathize. When all data disappear from consciousness, which has no other resource than employment and repetition of its old possessions its range must be narrowed. But the patient utilizes his old store of ideas as any other person uses his experiences and opinions, except perhaps on his worst days of excitement and agitation. Of course false memories and fantastic embellishments of real events may not be wanting to cover the lapses which he feels step by step. These fantastic stories almost always refer to ordinary events, but they of course do not correspond to the actual occurrences. The patient then fantastically and voluntarily embellishes ordinary events, e. g. his admission to the institution, or he speaks of excursions, of attending the theater during his residence in the hospital, or of transacting business; real sense impressions in the hospital are falsely interpreted and associated, when he speaks of prison, of cries and tumults, of visits of friends and their conversations, etc. The principal point is that he forgets all events and invents stories and never tells them twice alike. As he does not formulate them into delusions they do not change his personal relations to the world. His romancing is always the most active at times of greatest restlessness and 
anxiety, when illusions may also occur. I have never observed hallucinations; but they are reported by other authors. It is also evident that atypical cases occur. When, for example, an epileptic or otherwise hereditarily tainted individual succumbs to alcoholism the type of the alcoholic paresis must necessarily be complicated.

The further course of alcoholic neuritis or paresis with dementia differs in no way from that of all chronic diseases, $i$. e. the sensory, motor and psychical manifestations fluctuatingly improve. The sensory and motor disorders wholly disappear in time, although the reaction of degeneration is still long evident, whereas the psychical disorder in alcoholic neuritis seems only relatively reparable. In two cases of neuritis with amnesia, not of alcoholic origin, I have observed complete recovery from the psychical defect. The prognosis quoad valetudinem completam, in my opinion, is not good in alcoholic dementia.

The differential diagnosis between alcoholic paretic dementia and general progressive paresis is not difficult in somewhat pronounced cases, for far more points of difference than mutual symptoms exist. In progressive paresis the cranial nerves are the earliest and the most plainly affected usually; the absence of pupillary reaction, the tremor, vibration, incoordination of the lips, tongue and other facial muscles are what are most striking; in alcoholic paresis the words are well articulated, the pupils react. This paresis is ascending from the first; it first attacks the extremities and very seriously, and then only very exceptionally reaches the higher cranial nerves through the vagus. Sensation is much more markedly affected in alcoholic paretics, the muscles and nerve trunks are painful on pressure and the first considerably atrophied. Muscular atrophy also occasionally occurs in the latter stage of progressive paresis; but it is confined to several small muscles of the hands and feet. The initial headaches and subsequent paretic seizures are absent in alcoholics.

The psychosis of progressive paresis occurs in diverse forms, but the inability to understand their real condition is common to these patients, also to estimate money and figures, to consider the chances of a project; all this is absent in the alcoholic paretic, to say nothing of the peculiar grandiose delusions; he judges of his conditions and surroundings as well as before and makes no 
plans, whereas his memory is much weaker than that of the paretic. For this reason he utters false and in part fantastic statements as to his experiences.

Almost nothing can as yet be said of the pathologico-anatomical condition of the central nervous system. There are very few reports of autopsies and practically no microscopic examinations. To compile the conditions which have been presented by Korsakow, Serbaski, Suchanow, Giese and Pagenstecher there are found, also in young persons, oedema of the subarachnoid spaces, slight clouding of the meninges, the brain anemic and several cerebral arteries atheromatous. Several changes in the ganglion cells of the spinal cord, like vacuolation and pigmentation, are correctly regarded by the authors either as produced artificially or depending on other causes, as e. g. the pigmentation of the cells and vessels of the spinal cord in an alcoholic neuritic, who was likewise an epileptic. Oppenheim ${ }^{13}$ has proven a moderate atrophy of the cells of the anterior horn, diffuse or disseminated inflammatory conditions, whereas the peripheral nerves and muscles have not been examined with positive success. Macroscopically the nerves, particularly of the lower extremities, do not appear white, but yellowish; microscopically the medullary sheath. is found in fragments as well as an increase of nuclei in the sheath of Schwan; in hardened specimens the medullary sheath and axis cylinder are destroyed here and there, the perineurium thickened, Rosenheim ${ }^{14}$ found mast cells. The myositis ${ }^{15}$ has been investigated by Senator, Giese and Pagenstecher. There are increase of the muscle nuclei, hyperemia, atrophied fibres and pigment after extravasations. Giese and Pagenstecher found atrophied and degenerated fibres in the disc, loss of the striation and thickened nuclear intermediary substance. These authors especially point to the fact that these changes in the muscles cannot be secondary; they expressly assume a simultaneous disease of the nerves and muscles.

In regard to therapy it does not need to be especially stated that the hope of improvement depends materially on withdrawal of

"sehrbuch der Nervenkrankheiten, 1894, p. 350.

${ }^{10}$ Arch. f. Psych., Bd. XVII und XVIII.

${ }^{2 s}$ Zeitschr. f. klin. Med., XV. 
the pernicious agent. Electrotherapy has not met with signal success.

This is all that can be said in the present state of our knowledge. Alcoholic neuritis corresponds to what was formerly known as alcoholic paresis; infectious neuritis like it, as proven by recent investigations, completes the clinical type; but alcoholic neuritis has a longer premonitory stage and is not exactly like it, the individuals remaining psychical and somatic invalids in posttyphoid, puerperal, gastro-enteritic neuritis a subsequent dysmnesia and a certain paresis or loss of strength do not seem to be the rule. In any case many further observations are needed, but the number of the latter is small with respect to alcoholic paretics.

All the pathological conditions in which a pronounced amnesia is observed, like senescence, head trauma and the sequel of attempts at suspension, cannot here be included. 